Original Article

\title{
THERAPEUTIC EFFECT OF SILVER NANOPARTICLES AGAINST DIETHYL NITROSAMIN AND CARBON TETTRACHLORIDE-INDUCED HEPATOCELLULAR CARCINOMA IN RATS
}

\author{
MARWA T. HASSEN ${ }^{*}$, NAJAT JABBAR AHMED ${ }^{2}$, HANAA K. MOHAMED ${ }^{3}$ \\ ${ }^{1 * 3}, 3$ Department of Zoology, Faculty of Women for Arts, Science and Education, Ain Shams University, Cairo, Egypt, ${ }^{2}$ Erbil Technical Health \\ College, Erbil Polytechnic University, Erbil, Iraq \\ Email: meropinky87@gmail.com
}

Received: 21 Jun 2020, Revised and Accepted: 25 Jul 2020

ABSTRACT

Objective: Hepatic cancer is known as primary liver cancer and hepatocellular carcinoma (HCC). Newly silver nanoparticles gained importance due to its advantages and multiple potential such as molecular imaging agent, antimicrobial, wound healing, anti-inflammatory and anticancer activity. The current study deals to assess therapeutic property silver nanoparticles (AgNPs) against diethylnitrosamine (DENA), and carbon tetrachloride (CCL4) induced hepatic cancer.

Methods: Thirty male albino rats $(200-250 \mathrm{~g})$ were distributed into four groups and hepatic cancer was induced with a single intraperitoneal dose of $200 \mathrm{mg} / \mathrm{kg}$ body weight of DENA. Two weeks later, animals received subcutaneous injections of CCl4 once a week in a dose of $3 \mathrm{ml} / \mathrm{kg}$ body weight for 6 weeks. Serum biomarkers, antioxidants enzymes, inflammatory markers were evaluated to find the anti-proliferative potential of silver nanoparticles. Histological evaluation and microscopic reports were also done to document the results of the current work.

Results: AgNPs significantly recover the serum marker enzymes of hepatic parameter AST, ALT, ALP, and total bilirubin and also decreased the levels of NO, IL-6 and TNF- $\alpha$. Histopathological features also exhibited recovery of a hepatic architecture in cancer-induced rats. Moreover, the immunohistochemical investigation demonstrated that the levels of PCNA, and Caspase-3, which are hepatocarcinogenic markers, were significantly improved by AgNPs.

Conclusion: These results concluded that AgNPs showed promising curing effects on hepatocellular ailments.

Keywords: Hepatocellular carcinoma (HCC), Diethylnitrosoamine (DENA), Carbon tetrachloride (CCL4), Silver nanoparticles (AgNPs), Apoptosis, Interleukin-6(IL-6)

(C) 2020 The Authors. Published by Innovare Academic Sciences Pvt Ltd. This is an open access article under the CC BY license (http://creativecommons.org/licenses/by/4.0/) DOI: http://dx.doi.org/10.22159/ijpps.2020v12i9.38813. Journal homepage: https://innovareacademics.in/journals/index.php/ijpps.

\section{INTRODUCTION}

The liver is the largest solid organ and one of the most vital organs that functions as xenobiotic and drug, energy, protein and amino acid metabolism, storage of glucose in the form of glycogen, storage of vitamins, and regulation of hormonal functions. Ozougwu stated that a total loss of liver function might lead to death within minutes, indicating the liver's great importance. Hepatocellular carcinoma (HCC) is a life-threatening neoplasm that originated from hepatocytes, representing approximately $80 \%$ of liver cancer and $3^{\text {rd }}$ most common cancer-related death [1]. HCC is an extremely vascularized and malignant tumor that is responsible for poor survival and rapid recurrence in patients [2]. Human cancers are related to chronic inflammation caused by chemical, biological and, physical factors. The effect of inflammation-fibrosis-carcinoma axis acts as a bridge from inflammation to cancer, and therefore promotes inflamed liver development to fibrosis/cirrhosis and HCC [3]. Upon exposure to risk factors like alcohol, viruses, parasites and, toxic substances, the hepatic injury resulted in the degeneration and inflammation, leading to chronic liver diseases, which may further progress to different stages of fibrosis, cirrhosis, and HCC. HCC is the final stage of this process [3].

Drug-induced liver cancer in rats is an important tool to study primary HCC such as Ethanol, carbon tetrachloride $\left(\mathrm{CCl}_{4}\right)$, afatoxin, nitrosamines, amino azo dyes, aromatic amine and so on all are used to induce HCC in animal models. Diethylnitrosamine (DENA) is amongst the most essential natural carcinogenic agents, which is known to cause changes in the enzymes required in DNA repair replication and is regularly utilized as a cancer-causing agent to prompt liver carcinogenesis in mouse models [4].

DENA is a well-known potent hepatocarcinogenic agent present in tobacco smoke, water, cured and fried meals, cheddar cheese, agricultural chemicals, cosmetics, and pharmaceutical products [5]. In experimental induction of HCC in animal models, we use the two- stage application of chemicals for the initiation and promotion of hepatocellular tumors. The initiator in this protocol is a single injection of a dose of DENA. Two weeks later, animals received subcutaneous injections of $\mathrm{CCl}_{4}$ for $6 \mathrm{w}$ to promote the carcinogenic effect of DENA. Uehara et al. reported that DENA/CCl 4 mouse model differs from animal models utilizing either agent alone in that the resultant chronic liver fibrosis is accompanied by a dramatic increase in the liver tumor incidence, with $100 \%$ of the mice in the co-treatment group developing liver tumors by 5 mo of age.

The HCC is an extremely vascularized tumor, in which angiogenesis has a critical role in the progression, metastasis, and frequency [6]. One of the angiogenic stimulating factors is oxidative stress/inflammatory cascade. It enhances the vascular permeability and chemokine-mediated enrolment of leukocytes and platelets with major angiogenic cytokines and growth factors release. The most important of these are nitric oxide (NO), vascular endothelial growth factor (VEGF), platelet-derived growth factor (PDGF), interleukin-4 (IL-4), interleukin-8 (IL-8) and tumor necrosis factor-alpha (TNF- $\alpha$ ) [7]. Furthermore, dysregulated apoptosis has a crucial role in HCC tumorigenesis and acquired resistance to chemotherapy.

Nanotechnology, a concept in the field of science and technology in recent years, has also been likely to grow based on their demand, like other technologies. Nanoparticles are usually a cluster of atoms ranging between 1-100 $\mathrm{nm}$ in size and they exhibit new properties based on their size, distribution and morphology [8]. Many materials are synthesized in nanosize for various applications, including medicine, mechanical, biomedical, and electronics. Though the biological method is commonly adopted for the creation of silver nanoparticles, the use of plant extracts is widely spread studied due to its advantages over others [9].

Among the nanoparticles, nanosilver has potential applications in the field of biomedicine since silver has a disinfecting effect and has found 
uses in traditional medicines for a long time [10]. The AgNPs prevents VEGF-stimulated angiogenesis as well as cellular proliferation and migration induced by activated phosphatidylinositol-3-kinases/Protein kinase B (PI3K/Akt) signaling pathways [11, 12]. Moreover, different cytotoxic effects and reduction in cellular viabilities ending in antiproliferative effects through oxidative stress-apoptotic pathways were recognized by using AgNPs both in various cancer cell lines, including human hepatocellular carcinoma cell line HepG2 [13] and other in vivo cancer models regardless HCC models.

Among different plants, the seeds of Nigella sativa had shown to exhibit various medicinal properties such as anti-diabetic [14], antiallergic [15], anti-inflammatory, antibacterial, antioxidant and anticancer activity [16]. The aim of the present investigation was the therapeutic effect of synthesizing silver nanoparticles using seeds of Nigella sativa as a reducing agent on DENA/CCl4-induced liver cancer in animal models through contemplating the biochemical parameters, immune histology and histopathology of tissues.

\section{MATERIALS AND METHODS}

\section{Drugs and chemicals}

Diethylnitrosamine (N-nitrosodiethylamine; DENA; purity, 99.0\%) and $\mathrm{CCl}_{4}$ were purchased from Sigma-Aldrich Company, St. Louis USA. DENA was diluted in saline $(0.9 \% \mathrm{NaCl})$ while $\mathrm{CCl}_{4}$ was diluted in corn oil. AgNPs were synthesized using a green biosynthesis method by reducing the AgNO3 solution with aqueous extract of Nigella sativa according to [9].

\section{Preparation of aqueous silver nitrate}

Silver nitrate solution (1 M) was prepared and stored in an ambercolored bottle.

\section{Preparation of extract from seeds of nigella sativa}

The seeds of Nigella sativa were washed several times with deionized water. The extract used for the synthesis of silver nanoparticles was prepared by adding $20 \mathrm{~g}$ to $100 \mathrm{ml}$ of distilled water. The suspension was homogenized and centrifuged, after that the supernatant was collected and the extract obtained was filtered through Whatman No. 1 filter paper, finally, the filtrate was stored at $4{ }^{\circ} \mathrm{C}$

\section{Synthesis of silver nanoparticles}

Five different aliquots of the seed extracts (1-5 ml) were taken separately and $10 \mathrm{ml}$ of $1 \mathrm{mmol}$ silver nitrate solution was added with constant stirring and exposed to sunlight radiation. The color change of the solution was checked periodically; from yellow to dark brown indicated that the silver nanoparticles were synthesized.

\section{Induction of hepatocellular carcinoma}

Induction of HCC was through two consecutive stages: initiation and promotion by DENA and $\mathrm{CCl}_{4}$; respectively [17]. For initiation, DENA was injected i. p to each rat in a single dose of $200 \mathrm{mg} / \mathrm{kg} \mathrm{b}$. wt [18]. Two weeks later, animals received subcutaneous injections of $\mathrm{CCl}_{4}$ ( $\mathrm{CCl}_{4} /$ olive oil; $1: 1 ; 1 \mathrm{ml} / \mathrm{kg}$ ) once a week in a dose of $3 \mathrm{ml} / \mathrm{kg} \mathrm{b}$. wt for $6 \mathrm{w}$ to promote the carcinogenic effect of DENA [19].

30 adult male albino rats were employed in the present study. They were obtained from the Serum and Antigen Laboratories at Helwan. Their weight ranged between $(200-250 \mathrm{~g})$. The experimental protocols were carried out corresponding to the guidelines for the animal experiment, which was approved by the Ethical Committee of the Medical Research Center. Giza. Egypt (registration number: 13/165). Animals were allowed a one-week pre-experimentation period to adapt to laboratory conditions in order to avoid any complications along the course of the experiment. After one week acclimatization period, the rats divided into four groups; group I ( 5 rats): normal control, group II ( 5 rats): solvent control group: Rats were injected i. p. with 1 of ml olive oil for $6 \mathrm{w}$, group III (10 rats) DENA/CCl4-treated group (HCC group): Rats received a single dose of DENA (200 mg/kg b. wt i. p). Two weeks later, animals received subcutaneous injections of CCl4 once a week in a dose of $3 \mathrm{ml} / \mathrm{kg} \mathrm{b}$ wt for 6 w. Group IV (10 rats): DENA/ $/ \mathrm{CCl}_{4} / \mathrm{AgNPs}$-treated group: After induction of HCC, AgNPs were daily given by oral gavage in a dose of $300 \mathrm{mg} / \mathrm{kg} \mathrm{b}$. wt from the start of the $9^{\text {th }}$ week for $21 \mathrm{~d}$.

\section{Blood and liver sampling}

At the end of the experiment, blood samples for biochemical and biological analyses were collected from the heart in clean, dry test tubes. The collected blood was left to coagulate. After centrifugation at $4000 \mathrm{r}$. p. m. for $10 \mathrm{~min}\left(4^{\circ} \mathrm{C}\right)$, sera were separated and used for determination of aspartate aminotransferase (AST), alanine aminotransferase (ALT), alkaline phosphatase (ALP), total bilirubin, nitric oxide (NO) markers, interleukin (IL-6) and tumor necrosis factor-alpha (TNF- $\alpha$ ). Each liver was dissected out, washed in normal cold saline, and dissected into two parts. One part was embedded in $10 \%$ neutral buffered formalin for the histopathological and the part for immune-histochemical examinations.

\section{Biochemical analysis}

The activities of AST and ALT were assayed by the method of[20], while serum activity of ALP was determined according to the procedure of [21]. The colorimetric method of [22] was applied for the determination of serum contents total bilirubin. IL- 6 was determined using Abcam's Rat ELISA Kit (ab119548). Serum TNF- $\alpha$ was measured by ELISA. The VEGF was determined using an enzyme-linked immunosorbent assay (ELISA) kit.

\section{Histopathological examinations}

Liver tissues, preserved in neutral buffered formalin 10\% solution, were processed to obtain Formalin Fixed Paraffin Embedded (FFBE) blocks. Changes were assessed in histopathological sections at 3micron and then stained with haematoxylin and eosin ( $\mathrm{H}$ and $\mathrm{E}$ ).

\section{Immuno-histochemical study}

\section{Proliferating cell nuclear antigen (PCNA)}

Five-lm-thick neutral buffered formalin-fixed sections were deparaffinized in xylene, hydrated in a descending series of ethanol to phosphate-buffered saline (PBS; pH 7.5). Sections were prepared to quantify proliferating cell nuclear antigen (PCNA) and protein expression. The avidin-biotin complex immunoperoxidase staining system was used. Primary antibodies used were: monoclonal mouse anti-proliferating cell nuclear antigen (PCNA; clone PC 10; Dako Corporation, Carpentaria CA, Denmark). Tissue refreshment was performed using $3 \% \mathrm{H} 2 \mathrm{O} 2$ for $30 \mathrm{~min}$ at $100{ }^{\circ} \mathrm{C}$ and washed in two changes of PBS. The primary antibodies were then marked with biotinylated goat anti-mouse IgG antibody for $35 \mathrm{~min}$ at room temperature, washed in two changes of PBS; then the sections were incubated with streptavidin-conjugated peroxidase for $35 \mathrm{~min}$. After washing in PBS, the reaction was colored by exposing sections to 3,3diaminobenzidine (DAB) solution for $10 \mathrm{~min}$, then washed in distilled water ( 2 changes) and counterstained with $1 \%$ methy 1 green stain. After washing in tap water, the sections were dehydrated, cleared in xylene and mounted with Canada balsam. Control reaction was carried out by removing specific primary antibodies for PCNA.

\section{Caspase-3}

Immunohistochemical staining performed on $4-\mu \mathrm{m}$, formalin-fixed, paraffin-embedded sections using caspase 3 antibodies at 1:50 dilution. Antigen retrieval was performed in all cases by steam heating the slides in a 1-mmol/l solution of EDTA ( $\mathrm{pH} \mathrm{8.0)} \mathrm{for} 30$ min. After blocking of endogenous biotin, staining was performed using an automated immunostainer (DAKO) followed by detection by using a streptavidin-biotin detection system. Positive and negative control sections used for each assay.

\section{Statistical analysis}

Data were coded and entered using the statistical package for the Social Sciences (SPSS) version 25 (IBM Corp., Armonk, NY, USA) Data were summarized using mean and standard error of the mean (SEM) for quantitative variables. Comparisons between groups were done using analysis of variance (ANOVA) with multiple comparisons post hoc test for comparison between every two groups [23].

\section{RESULTS}

\section{Impact of AgNPs on serum liver enzymes and total bilirubin}

It was evident from the table 1, fig. 1, and fig. 2 that DEN/CCl4 control group showed an elevated level of all hepatic parameters i.e. 
AST, ALP, ALT and serum total bilirubin with respect to a normal control group. $\mathrm{DENA} / \mathrm{CCl}_{4}$ induced hepatic cancer group when treated with AgNPs significantly declined the levels of all hepatic serum markers.

Table 1: Effects of AgNPs on liver enzymes activities and total bilirubin levels in rats

\begin{tabular}{lllll}
\hline $\begin{array}{l}\text { Groups } \\
\text { Parameters }\end{array}$ & Normal control (NC) & Solvent control (SC) & HCC group & HCC+AgNPs group (300 mg/kg) \\
\hline ALT $(\mathrm{ng} / \mathrm{ml})$ & $27.67 \pm 0.56$ & $28.33 \pm 1.17$ & $239.67 \pm 9.64^{*} \#$ & $64 \pm 5.3^{*} \# \$$ \\
AST $(\mathrm{ng} / \mathrm{ml})$ & $38.5 \pm 1.36$ & $42.67 \pm 0.92$ & $265 \pm 7.96^{*} \#$ & $86.33 \pm 2.01^{*} \# \mathbf{}$ \\
ALP $(\mathrm{mg} / \mathrm{ml})$ & $57.5 \pm 1.12$ & $68 \pm 0.73$ & $263.33 \pm 5.58^{*} \#$ & $89.67 \pm 3.66 * \# \$$ \\
Total bilirubin $(\mathrm{mg} / \mathrm{ml})$ & $21.33 \pm 1.52$ & $32 \pm 1.1$ & $206.67 \pm 9.19^{*} \#$ & $71 \pm 3.71^{*} \$ \$$ \\
\hline
\end{tabular}

Values are presented as mean $\pm \mathrm{SEM}^{*}$ : statistically significant compared to corresponding value $\mathrm{NC}$ group $(\mathrm{P}<0.05)$ \#: statistically significant compared to the corresponding value in SC group $(\mathrm{P}<0.05) \$$ : statistically significant compared to the corresponding value in $\mathrm{HCC}$ group $(\mathrm{P}<0.05)$

\section{Impact of AgNPs on serum Il-6, TNF- $\alpha$ and VEGF levels}

Table 2 and fig. 3 speaks about the proinflammatory cytokines (TNF$\alpha$, IL- 6 ) and the raised level of TNF- $\alpha$ and IL- 6 in DEN/CCl4-induced rats was significantly decreased by AgNPs administration manner toward the finish of the experiment. In other words, VEGF showed the same result as that of TNF $\alpha$ and IL-6. DENA/CCl 4 induced hepatocarcinogenesis demonstrated the elevated level of VEGF with respect to a normal control rats.

Table 2: Effects of AgNPs on serum Il-6, TNF- $\alpha$ and VEGF levels in rats

\begin{tabular}{lllll}
\hline $\begin{array}{l}\text { Groups } \\
\text { parameters }\end{array}$ & Normal control (NC) & Solvent control (SC) & HCC group & $\begin{array}{l}\text { HCC+AgNPs group (300 } \\
\text { mg/kg) }\end{array}$ \\
\hline IL-6 (pg/ml) & $96 \pm 1.93$ & $107.67 \pm 2.49$ & $364.33 \pm 14.77^{* \#}$ & $167.67 \pm 5.73^{* \# \$}$ \\
TNF-alpha (pg/ml) & $96 \pm 1.93$ & $110.33 \pm 3.66$ & $474.33 \pm 22.85^{* \#}$ & $173.33 \pm 9.19^{* \# \$}$ \\
VEGF $(\mathrm{pg} / \mathrm{ml})$ & $53.67 \pm 4.4$ & $63.67 \pm 2.84$ & $432 \pm 28.59^{* \#}$ & $116.67 \pm 13.82^{\$}$ \\
\hline
\end{tabular}

Values are presented as mean $\pm \mathrm{SEM}^{*}$ : statistically significant compared to corresponding value $\mathrm{NC}$ group (P<0.05) \#: statistically significant compared to the corresponding value in $\mathrm{SC}$ group $(\mathrm{P}<0.05) \$$ : statistically significant compared to corresponding value in $\mathrm{HCC}$ group $(\mathrm{P}<0.05)$.

Table 3: Effects of AgNPs on nitric oxide (NO) levels in rats

\begin{tabular}{lllll}
\hline $\begin{array}{l}\text { Groups } \\
\text { parameters }\end{array}$ & Normal control (NC) & Solvent control (SC) & HCC group & HCC+AgNPs group (300 \\
$\mathbf{m g} / \mathbf{k g})$
\end{tabular}

Values are presented as mean $\pm \mathrm{SEM}^{*}$ : statistically significant compared to corresponding value $\mathrm{NC}$ group (P<0.05) \#: statistically significant compared to the corresponding value in SC group $(\mathrm{P}<0.05) \$$ : statistically significant compared to the corresponding value in $\mathrm{HCC}$ group

\section{Impact of AgNPs on serum nitric oxide (NO) levels}

DENA/ $\mathrm{CCl}_{4}$ induced rats affirmed the enhanced level of NO, when contrasted with normal control rats. AgNPs treatment revealed the dose-dependent lessening in NO, which confirms the antioxidant property of treatment (table 3 and fig. 4).

\section{Impact of AgNPs on DENA/CCl 4 -induced hepatic} histopathological changes

Histopathological examination of liver sections of a normal control group (Group I) stained with $\mathrm{H}$ and $\mathrm{E}$ showed normal hepatic configuration. The liver cells are arranged in the form of cords radiating from the central vein to the periphery (fig. 5). Liver sections of Groups II, which was administered with olive oil without the induction of HCC, also showed the features of normal liver, indicating that there is no adverse effect of the olive oil on the liver (Fig.6). In contrast, the sections of the liver from HCC control group (Group III) showed a loss of lobular architecture. It also evidenced the features of necrosis, apoptosis, and diffused macrosteatosis (fig. $7,8)$. It also revealed the dilatation and proliferation of bile duct and fatty degeneration. DENA/CCl 4 /AgNPs-treated group in a dose of (300 $\mathrm{mg} / \mathrm{kg}$ body weight) showed marked improvements with almost restored lobular architecture and reduction in fatty degeneration (fig. 9).

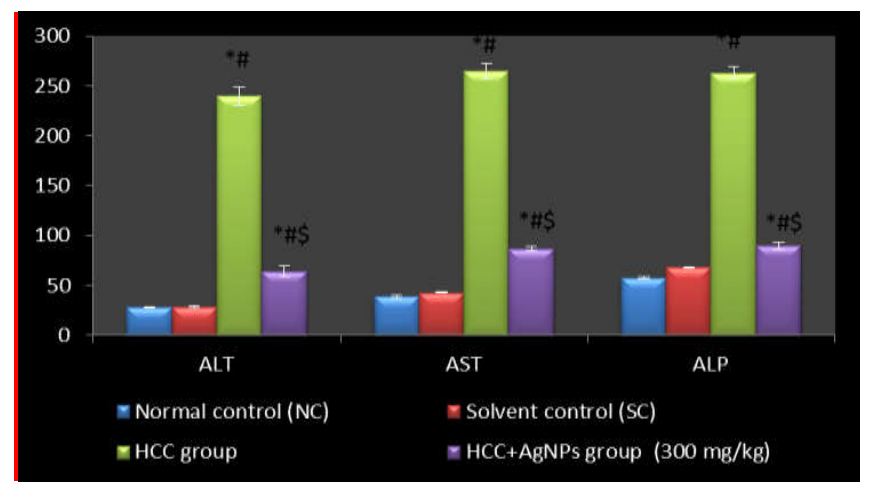

Fig. 1: Effects of AgNPs on liver enzymes activities in rats 


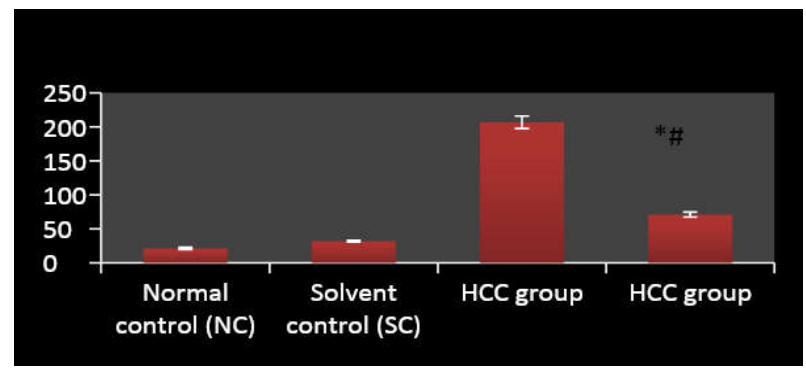

Fig. 2: Effects of AgNPs on total bilirubin levels in rats

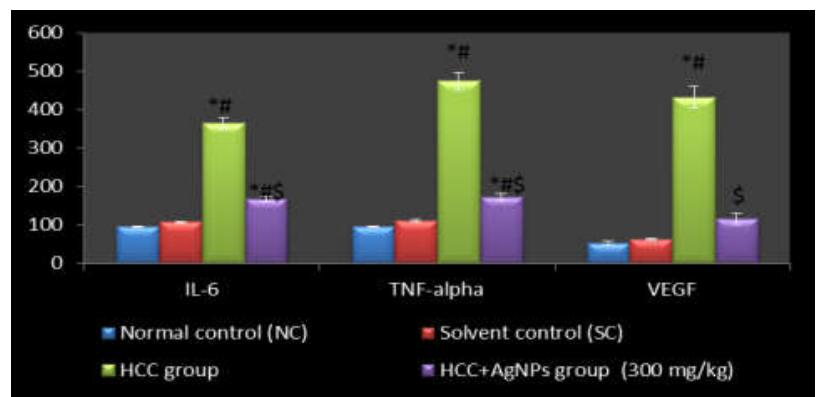

Fig. 3: Effects of AgNPs on serum Il-6, TNF- $\alpha$ and VEGF levels in rats

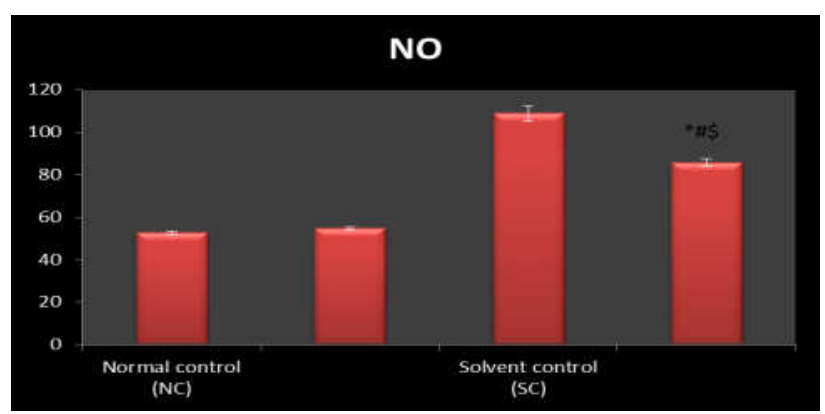

Fig. 4: Effects of AgNPs on nitric oxide (NO) levels in rats

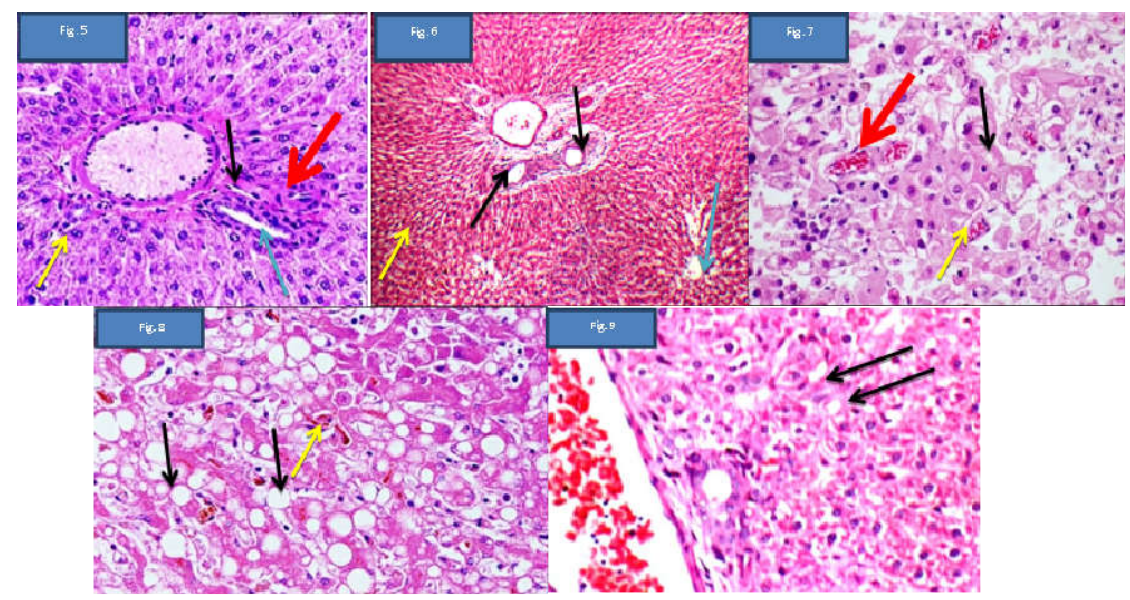

Fig. 5: (Control): high power view showing average portal tract (black arrow) with average portal vein (PV), average bile ducts (blue arrow), average hepatic artery (red arrow), and average hepatocytes in peri-portal area (yellow arrows) (HandE X 400). Fig. 6: (SC group) shows liver showing average portal tract (black arrow) with average portal vein (PV) and average bile ducts (BD), average central veins (blue arrow) and average hepatocytes (yellow arrow) (HandE X 200). Fig. 7: (HCC group) bile duct proliferation and hemorrhage (red arrow) more apoptotic nucleus ((black arrow) and show necrotic area (yellow arrows) (HandE X 400). Fig. 8: (HCC group) liver section showed diffused macrosteatosis (black arrow) and apoptotic nuclei (yellow arrows) (HandE X 400). Fig. 9: (HCC+AgNPs group) high power view showing marked improvement with portal tract with dilated congested portal vein (PV), average bile ducts (BD), and hepatocytes showing mild micro-vesicular steatosis in peri-portal area (black arrows) (HandE X 400) 


\section{Immunohistochemical results}

Proliferating cell nuclear antigen (PCNA) immune staining reaction was confined to the nuclei. The reaction product was present in different patterns from a faint to strong densely stained nuclear granular reaction filling the whole nucleus. Only moderately to strongly stained nuclei were considered as positive. Sections for the control reaction gave a negative PCNA stain. In the normal control liver sections, there were a few numbers of PCNA positive nuclei (fig. 10). Examination of liver sections in group II after receiving olive oil injection showed few numbers of PCNA positive nuclei the same as the normal group. Examination of liver sections of HCC group showed more predicted number of PCNA positive nuclei with strong intensity of immunostaining (fig. 11 and 12). After AgNPs administration there was an obvious decrease in the number of PCNA positive nuclei as compared with HCC group (fig. 13).

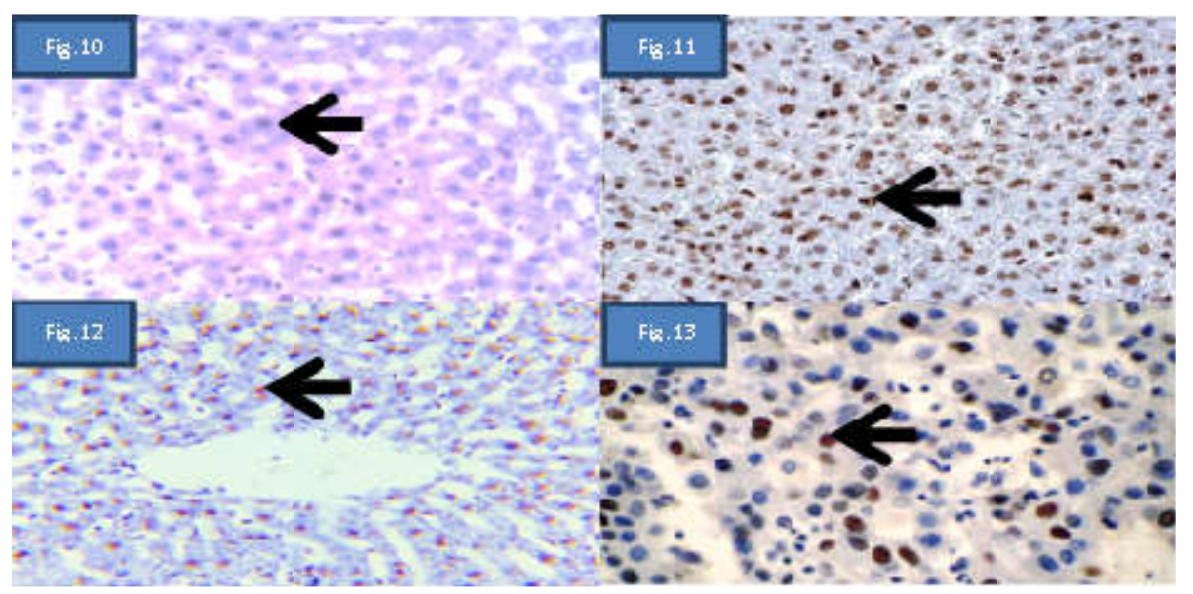

Fig. 10: (control and SC groups): liver section of normal control rat showing few PCNA positive hepatocytes nuclei (arrows), (X 400). Fig. (11and12): (HCC group): Liver section post DEN/CCL 4 injection showing increase in the number of PCNA positive nuclei (arrows), (X 400). Fig. 13: (HCC+AgNPs group) Photomicrographs of hepatic sections revealed mild expressions of PCNA cells of hepatocyte, (arrows), (X 400)

Immunohistochemistry was used for the detection of caspase-3positive cells in liver samples. Immunohistochemical analysis of liver sections of the normal control group showed classical immunoreactivity to cleaved caspase-3 (fig. 14). In contrast, the liver sections of the hepatic cancer-induced group (HCC group) showed increased immunoreactivity to cleaved caspase- 3 compared to the normal control group (fig. 15), Immunoreactivity of caspase-3 toward hepatocytes in the liver sections of the group treated with AgNPs was analyzed to compare the efficacy of the target of green biosynthesized of AgNPs by the seeds of Nigella sativa. Many hepatocytes showed decreased immunoreactivity to cleaved caspase-3 (fig. 16).

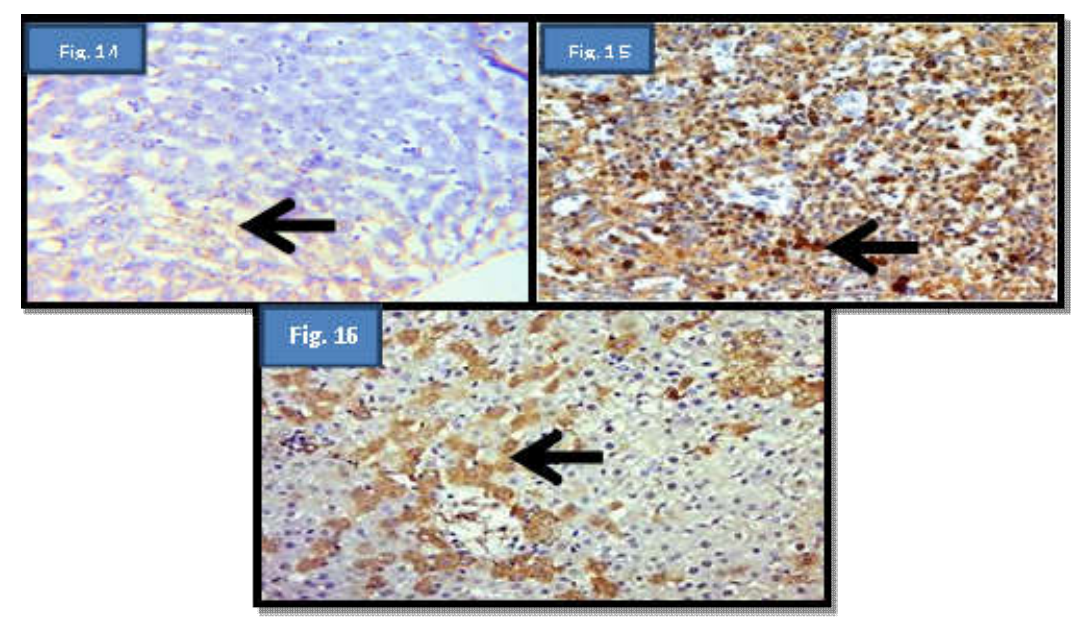

Fig. 14: hepatic section of control and solvent control rats showing low expressions of caspase-3 immune reactive cells as cytoplasmic brownish color, (arrow), (HandE X 400). Fig. (15): hepatic tissues of HCC rats showing wide spread of positive immune reactive cells for caspase-3 (arrows), (HandE X 400). Fig.(16): Photomicrographs of hepatic sections of HCC rats treated with AgNPs showing low expression for caspase-3, (arrows), (HandE X 400)

\section{DISCUSSION}

Hepatocarcinogenesis is a multistage process with the intervention of multiple risk factors such as chemical exposure [24]. In the DENA/CCl 4 -chemical model of HCC in animals, a multi-step of hepatic carcinogenesis is achieved, where the DENA-initiation stage is followed by the $\mathrm{CCl}_{4}$-promotion stage. DENA is an $\mathrm{N}$-nitroso alkylating agent which is quickly metabolized and collected in the liver, finishing in the formation of numerous DNA adducts such as the $\mathrm{O}_{4}$-ethyldeoxythymidine and lastly mutations [17]. The 
promotion with $\mathrm{CCl}_{4}$ is the hepatic cirrhosis, carcinogenesis, and HCC simulating the human histopathological and clinical pictures [6]. The present study was an endeavor to the silver nanoparticles of a plant extract with a result to control the development of hepatic cancer in rats.

In the present study, DENA/CCl 4 -induced oxidative stress can induce liver tissue damage and hence modify its function. Zhao et al. recorded that the AST, ALT, ALP, and total bilirubin serum levels are indicators for hepatic function, their increase is correlated with the hepatic injury. DEN hepatic injury is related to the disturbance in hepatocytes membrane instability and metabolism resulting in alterations of the serum levels of these enzymes. Al-Rejaie et al. mentioned that increase of ALT and AST levels are specific to hepatocellular disturbance [41]. ALP is a liver function enzyme that related to the membrane lipid in canalicular ducts. ALP increase in serum reflects the biliary flow disturbance. So, the extra or intrahepatic interference with the bile flow leads to the elevation of ALP serum levels. Also, various studies documented the increase in ALT and AST levels may be due to the spillage of these cytosolic enzymes and, moving towards the circulatory system occurred because of hepatic destruction after DEN introduction. This is beginning of hepatocellular destruction because of the hypofunction of liver and interruption in the biosynthesis of these serum markers enzymes, with changing the penetrability of the liver cell membrane [26].

The current result revealed a significantly reduction in the levels of these enzymes after AgNPs administration because of changing the permeability and integrity of liver membrane. Such a result runs in full agreement with that of [27].

Bilirubin is produced as a metabolic product of haemoglobin, which involves in conjugation with glucuronic acid in hepatocytes. Estimation of serum bilirubin imparts a main role in estimation of hepatic capacity, and any irregular increment in the levels of serum bilirubin demonstrates hepatobiliary illnesses and inflammation of liver function[28]. Also, Rajkapoor et al. reported that a significant increase in the level of serum bilirubin might be due to the mass hindrance of the conjugation response and release of unconjugated bilirubin from damaged hepatocytes [29]. Treatment with AgNPs decreased the content of serum bilirubin and involves in the regeneration of normal activity of liver.

IL-6 is an immunoregulatory cytokines produced by cancer cells and associated macrophages, its high serum level is associated with specific immune and metabolic alterations that lead to cancer cachexia, one of the main causes of death in cancer. During inflammation, IL- 6 regulates the response of certain liver-specific transcription factors [30]. In addition, IL-6 is a positive regulator of growth and play a role in the proliferation, differentiation, and apoptosis of myeloid cells [31]. It inhibits apoptosis in cancer cells and stimulates angiogenesis. It regulates growth in solid tumors through paracrine and autocrine actions Also, IL-6 is associated with the stage of tumor and survival. IL- 6 acts as a mutagenic, motogenic, morphogenic, proneoangiogenic, and hepatocyte growth factor in HCC and thus plays a role in HCC carcinogenesis. Jin et al. reported that IL- 6 is produced by Kupffer cells and stimulates compensatory regeneration which may be important in DENA-induced hepatocarcinogenesis [32]. IL-6 is considered to be an hepatoprotective cytokine, although it has also been shown that persistent high levels of IL- 6 cause liver damage.

HCC is likely to produce angiogenic factors. VEGF is considered the strongest stimulator for angiogenesis, and plays an important role in the course of carcinogenesis and metastasis [33]. VEGF is significantly elevated in HCC as HCC is a highly vascular tumor, and tumor angiogenesis is critical for both its growth and metastasis [35]. As an inflammatory, apoptotic, and angiogenic cytokine, TNF- $\alpha$ has various important roles in HCC pathogenesis. It leads to superoxide formation, with either activation of the caspase-8, and/or induction of necroptosis. The necroptosis cell death is a consequence of caspase inactivity with the engagement of death receptors mainly TNF receptor-1 (TNFR1). Moreover, the upregulated expression of VEGF/VEGF receptors and IL-8 are evidenced after TNF- $\alpha$ production [36]. Recently, Aboubakr et al. reported that circulating pro-inflammatory cytokines, such as TNF- $\alpha$ and IL-6 which triggers hepatic injury, were increased at least in part by a free-radical-mediated apoptotic mechanism [37].

In the current study, the DENA/CCl 4 -challenging showed increases in the NO. In HCC, poor prognosis is associated with upregulated angiogenic factor and excessive tumor vasculature. In dynamic paracrine and autocrine manners, the hepatic stromal, tumor and stellate cells are considering major sources of these angiogenic factors [38]. The higher hepatic NO production is playing very important roles in neoplastic transformation and progression through DNA damage. Moreover, the hepatic cancer cells with multidrug resistance protein-1 (MDR1) phenotype display marked inducible nitric oxide synthase expression and NO levels. In this investigation, we observed that AgNPs decreased NO levels in DENA/ $\mathrm{CCl}_{4}$ induced liver cancer. These manifested that AgNPs can lessen reactive oxygen species and diminishing oxidative destruction to the hepatic tissues other than enhancing the action of enzymatic antioxidant parameters.

In this study, the histological study of the livers of those rats exposed to DENA/ $\mathrm{CCl}_{4}$ showed the existence of several histological changes, including areas of necrosis, apoptotic cells which are extremely rare in normal livers which might be due to the excessive free radicals generation during DENA/CCl ${ }_{4}$ administration. Such findings strongly suggest the ability of DENA to initiate hepatocarcinogenesis with the interactive effect of $\mathrm{CCl}_{4}$. The same observation was documented by many authors $[39,40]$. The histological features suggested that AgNPs are effective in reducing DEN-induced hepatocarcinogenesis.

Immunohistochemistry was used for the detection of PCNA and caspase-3-positive cells in liver samples. PCNA is a cofactor of DNA polymerase-delta and an index of the rate of cell turnover or cell proliferation [41]. PCNA is involved in protein-protein interactions [42] and in the DNA damage tolerance pathway known as postreplication repair [43]. The present work demonstrated that PCNA immuno-histochemically as potential molecular biomarkers. These investigations were done to improve our understanding of histopathological changes. It was suggested that cancer associated with elevated levels of PCNA whose levels were used as a predictive marker in various cases [44]

Caspases are aspartate-specific cysteine proteases and members of the interleukin-1 (IL-1) $\beta$-converting enzyme family. These enzymes are produced in inactive forms and are activated in a protease cascade. Caspases are often classified into initiators (caspase-1, -2 , $-4,-5,-8,-9,-10,-11,-12$ ) and effector caspases (caspase- $3,-6$, -7). The latter ones, with caspase- 3 being considered the most important member, are responsible for the execution of apoptosis or programmed cell death [45]. Apoptosis is a form of programmed cell death characterized by DNA fragmentation, cytoplasmic shrinkage, membrane changes, and cell death without lysis or damage to the neighboring cells. Apoptosis is important during development, for normal tissue homeostasis, and as a protective mechanism to get rid of damaged cells owing to diseases or toxins. On the contrary, inappropriate apoptosis has been implicated in the development of cancer, neurodegenerative disorders, and autoimmune diseases [46]. Caspases take part in both the intrinsic and extrinsic apoptosis pathways. However, caspase-3, also known as the executioner caspase, is responsible for the morphological changes such as chromatin condensation, DNA breakdown and laddering, and breakdown of membrane proteins [47].

Many attempts have been made to use AgNPs as an anticancer agent and they have all turned up to be positive [48]. The size reduction of nanoparticles plays an important role in improving their bioavailability and compatibility for therapeutical applications in diseases like cancer. Developing more effective and less toxic anticancer agents, including natural products, are necessary to prevent or delay the process from hepatocarcinogenesis [49]. AgNPs have been recorded to extend chemopreventive activities by controlling the tumor in vivo [50]

\section{CONCLUSION}

In conclusion, based on the present study results, we suggest the therapeutic effect of AgNPs synthesized by the green method using Nigella sativa against diethylnitrosamine and carbon tetrachloride- 
induced hepatocellular carcinoma in rats. AgNPs would exert a chemopreventive effect by restoring the activities of hepatic marker enzymes and lessen reactive oxygen species and diminishing oxidative destruction to the hepatic tissues during hepatocarcinogenesis.

\section{FUNDING}

Nil

\section{AUTHORS CONTRIBUTIONS}

All the authors have contributed equally.

\section{CONFLICT OF INTERESTS}

Declared none

\section{REFERENCES}

1. Zhu RX, Seto WK, Lai CL, Yuen MF. Epidemiology of hepatocellular carcinoma in the asia-pacific region. Gut Liver 2016;10:332.

2. Mishra S, Hora S, Shukla V, Das M, Kharkwal H, Katare DP. Sustained release tablets of sorafenib-silibinin combinations for the treatment of hepatocellular carcinoma. Int J Appl Pharm 2018;10:117-24.

3. Ding Y, Peng Z, Ding L, Peng Y. Baishouwu extract suppresses the development of hepatocellular carcinoma via TLR4/MyD88/NF-kB. Pathway 2019;10:1-14.

4. Ramakrishnan G, Augustine T, Jagan S, Vinodhkumar R, Devaki $\mathrm{T}$. Effect of silymarin on $\mathrm{N}$-nitrosodiethylamine induced hepatocarcinogenesis in rats. Exp Oncol 2007;29:39-44.

5. Wang F, Qu W, Li Y, Liu H, Li B, Qi J, et al. Diethyl nitrosamine alone was not recommended for primary hepacellular carcinoma model in rats. Int J Clin Exp Pathol 2016;9:10346-50.

6. Uehara T, Ainslie GR, Kutanzi K, Pogribny IP, Muskhelishvili L Izawa $\mathrm{T}$, et al. Molecular mechanisms of fibrosis-associated promotion of liver carcinogenesis. Toxicol Sci 2013;132:53-63.

7. Muto J, Shirabe K, Sugimachi K, Maehara Y. Review of angiogenesis in hepatocellular carcinoma: Angiogenesis in hepatocellular carcinoma. Hepatol Res 2015;45:1-9.

8. Satyavani K, Gurudeeban S, Balasubramanian TR. Biomedical potential of silver nanoparticles synthesized from calli cells of Citrullus colocynthis(L.) Schrad. J Nanobiotechnol 2011;9:43.

9. Reshi MS, Uthra C, Yadav D, Sharma S, Singh A, Sharma A, et al Silver nanoparticles protect acetaminophen-induced acute hepat otoxicity: a biochemical and histopathological approach. Regulatory Toxicol Pharmacol 2017;90:364.

10. Priyadarshni KC, Mahalingam PU. Antimicrobal and anticancer activity of silver nanoparticles from edible mushroom: a review. Asian J Pharm Clin Res 2017;10:37-40.

11. Gurunathan S, Lee KJ, Kalishwaralal K, Sheikpranbabu S, Vaidyanathan R, Eom SH. Antiangiogenic properties of silver nanoparticles. Biomaterials 2009;30:6341-5.

12. Kalishwaralal K, Banumathi E, Pandian SRK, Deepak V, Muniyandi J, Eom SH, et al. Silver nanoparticles inhibit VEGF induced cell proliferation and migration in bovine retinal endothelial cells. Colloids Surf B Biointerfaces 2009;73:51-7.

13. Zhu B, Lin N, Zhang M, Zhu Y, Cheng H, Chen S, et al. Activated hepatic stellate cells promote angiogenesis via interleukin-8 in hepatocellular carcinoma. J Transl Med 2015;13:365.

14. Hader A, Aqel M, Hasan Z. Hypoglycemic effects of the volatile oil of Nigella sativa seeds. Pharmaceutical Biol 1993;31:96-100.

15. Kalus U, Pruss A, Bystron J, Jurecka M, Smekalova A, Lichius JJ, et al. Effect of Nigella sativa (black seed) on subjective feeling in patients with allergic diseases. Phytother Res 2003;17:1209-14.

16. Bourgou S, Pichette A, Marzouk B, Legault J. Antioxidant, antiinflammatory, anticancer and antibacterial activities of extracts from Nigella sativa (Black cumin) plant parts. J Food Biochem 2012;36:539-46.

17. Motawi TK, El-Boghdady NA, El-Sayed AM, Helmy HS. Comparative study of the effects of PE gylated interferon- $\alpha 2 \mathrm{a}$ versus 5-fluorouracil on cancer stem cells in a rat model of hepatocellular carcinoma. Tumor Biol 2016;37:1617-25.

18. Sarkar A, Basak R, Bishayee A, Basak J, Chatterjee M. BCarotene inhibits rat liver chromosomal aberrations and DNA chain break after a single injection of diethylnitrosamine. Br J Cancer 1997;76:855-61.
19. Dakshayani KB, Subramanian P, Manivasagam T, Mohamed EM, Manoharan S. Melatonin modulates the oxidant-antioxidant imbalance during N-nitrosodiethylamine induced hepatocarcinogenesis in rats. J Pharm Pharm Sci 2005;8:316-21.

20. Bergmeyer HU, Scheibe P, Wahlefeld AW. Optimization of methods for aspartate aminotransferase and alanine aminotransferase. Clin Chem 1978:24:58-73.

21. Belfield A, Goldberg D. Colorimetric determination of alkaline phosphatase activity. Enzym 1971;12:561-6.

22. Walter M, Gerade H. A colorimetric method for determination of bilirubin in serum and plasma. Micro Chem J 1970;15:231-6.

23. Chan YH. Biostatistics102: quantitative data-parametric and non-parametric tests. Singapore Med J 2003;44:391-6.

24. Singh A, Dar MY, Joshi B, Sharma B, Shrivastava S, Shukla S. Phytofabrication of silver nanoparticles: novel drug to overcome hepatocellular ailments. Tox Rep 2018;5:333-42.

25. Al-Rejaie SS, Aleisa AM, Al-Yahya AA. Progression of diethylnitrosamine-induced hepatic carcinogenesis in carnitinedepleted rats. World J Gastroenterol 2009;15:1373-80.

26. Erejuwa 00, Sulaiman SA, Wahab MS, Sirajudeen KNS, Salleh MS, Gurtu S. Hepatoprotective effect of tualang honey supplementation in streptozotocin-induced diabetic rats. Int J Appl Res Nat Prod 2011;463:39-44.

27. Singha D, Singhb M, Yadava E, Fallsc N, Dangid DS, Kumarc V, et al. Attenuation of diethylnitrosamine (DEN)-Induced hepatic cancer in experimental model of wistar rats by Carissa carandas embedded silver nanoparticles. Biomed Pharmacother 2018;108:757-65.

28. Pal S, Bhattacharjee A, Mukherjee S, Bhattacharya K, Mukherjee S, Khowala S. Effect of alocasia indica tuber extract on reducing hepatotoxicity and liver apoptosis in alcohol intoxicated rats. Biomed Res Int 2014:10. https://doi.org/10.1155/2014/349074

29. Rajkapoor B, Jayakar B, Murugesh N, Sakthiskaran D. Chemoprevention and cytotoxic effect of Bauhinia variegata against $\mathrm{N}$-nitrosodiethylamine induced liver tumors and human cancer cell lines. J Ethnopharmacol 2006;104:407-9.

30. Porta C, De Amici M, Quaglini S, Paglino C, Tagliani F, Boncimino A, et al. Circulating interleukin-6 as a tumor marker for hepatocellular carcinoma. Ann Oncol 2008;19:353-8.

31. Łukaszewicz M, Mroczko B, Szmitkowski M. Clinical significance of interleukin-6 (IL-6) as a prognostic factor of cancer disease. Pol Arch Med Wewn 2007;117:247-51.

32. Jin X, Zimmers TA, Perez EA, Pierce RH, Zhang Z, Koniaris LG. Paradoxical effects of short and long-term interleukin- 6 exposure on liver injury and repair. Hepatology 2006;43:474-84.

33. El-Houseini ME, Mohammed MS, Elshemey WM. Enhanced detection of hepatocellular carcinoma. Cancer Control 2005;12:248-53.

34. Tan A, Kim R, El-Gazzaz G. Serum vascular endothelial growth factor level in patients with hepatocellular carcinoma undergoing liver transplantation: experience of a single Western center. Int J Organ Transplant Med 2012;3:42-51.

35. Darvesh AS, Aggarwal BB, Bishayee A. Curcumin and liver cancer: a review. Curr Pharm Biotechnol 2012;13:218-28.

36. Talaat RM, Adel S, Salem TA, Nasr MI. Correlation between angiogenic/inflammatory mediators in Wister rat model of liver dysplasia. J Immunoassay Immunochem 2016;37:472-84.

37. Aboubakr EM, Taye A, Aly OM, Gamal-Eldeen AM, El-Moselhy MA. Enhanced anticancer effect of combretastatin A-4 phosphate when combined with vincristine in the treatment of hepatocellular carcinoma. Biomed Pharmacother 2017;89:36-46.

38. Otto W, Sierdzinski J, Krol M, Wolinska E, Feliksbrot Bratosiewicz M, Wilkowojska U. Thvalue of tumor angiogenesis activity for stratification of HCC patients. Int J Clin Exp Med 2017;10:4200-13.

39. Barretto OC, Zyngier SB. Acquired disturbance of erythrocyte glutathione reductase in experimental tumors. J Cancer Res Clin Oncol 1984;108:252-3.

40. Jim JH, Jung JH, Kim SS, Yoon JU, Park JD, Choi BS. Twentyeight-day inhalation toxicity study of silver nanoparticles in sprague dawley rats. Inhal Toxicol 2007;19:857-71.

41. Freudenthal BD, Ramaswamy S, Hingorani MM, Washington MT. Structure of a mutant form of proliferating cell nuclear 
antigen that blocks translation DNA synthesis. Biochemistry 2008;47:13354-61.

42. Maga G, Hubscher U. Proliferating cell nuclear antigen (PCNA): a dancer with many partners. J Cell Sci 2003;116:3051-60.

43. Lehmann AR, Fuchs RP. Gaps and forks in DNA replication: rediscovering old models. DNA Repair 2006;5:1495-8.

44. Czyzewska J, Guzinska Ustymowicz K, Lebelt A, Zalewski B, Kemona A. Evaluation of proliferating markers Ki-67, PCNA in gastric cancers. Rocz Akad Med Bialymst 2004;49:64-6.

45. Li J, Yuan J. Caspases in apoptosis and beyond. Oncogene 2008;27:6194-206.

46. Jones JR, Kong L, Hanna MGIV, Hoffman B, Krencik R, Bradley R, et al. Mutation in GFAP disrupt the distribution and function of organelle in humanastrocytes. Cell Report 2018;25:947-58.
47. D’Amelio M, Cavallucci V, Cecconi F. Neuronal caspase-3 signaling: not only cell death. Cell Death Differ 2010;17:110414.

48. Vaidyanathan R, Kalishwaralal K, Gopalram S, Gurunathan S. Nano silver-the burgeoing therapeutic molecule and its green synthesis. Biotechnol Adv 2009;27:924-37.

49. Tabone M, Pellicano R. Prevention of intrahepatic hepatocarcinoma recurrence in patients with viral cirrhosis: two potential options. Minerva Gastroenterol Dietol 2006;52:47-52.

50. Antony JJ, Sithika MAA, Joseph TA, Suriyakalaa U, Sankarganesh A, Siva D, et al. In vivo antitumor activity of biosynthesized silver nanoparticles using ficus religiosa as a nanofactory in DAL induced mice model. Colloids Surf B 2013;108:185-90. 